\title{
resin cements containing different concentrations of ethyl 4-(dimethylamino)benzoate and 2-(dimethylamino)ethyl methacrylate as co-initiators
}

\author{
Kamila Menezes Guedes de Andrade ${ }^{a}$, Alan Rodrigo Palialol ${ }^{a}$, \\ Ailla C. Lancellotti ${ }^{b}$, Flávio Henrique Baggio Aguiar ${ }^{a}$, David C. Watts ${ }^{c, 1}$, \\ Luciano Souza Gonçalves ${ }^{d}$, Adriano Fonseca Lima ${ }^{e, *}$, \\ Giselle Maria Marchi ${ }^{a}$ \\ a Department of Restorative Dentistry, Piracicaba Dental School, State University of Campinas, Av Limeira, 901 Mail \\ Box 52, Piracicaba, Sao Paulo, Zip Code 13414-903, Brazil \\ b Department of Restorative Dentistry, Federal University of Rio Grande do Sul-UFRGS, Rua Ramiro Barcelos, 2492- \\ Santa Cecilia, Zip-Code 90035003, Porto Alegre, RS, Brazil \\ c School of Dentistry and Photon Science Institute, JR Moore Building, University of Manchester, Oxford Road, \\ Manchester M13 9PL, United Kingdom \\ d Dental School, University of Uberaba, Campus Centro - Av. Guilherme Ferreira, 217-Centro, Zip Code: 38010-200, \\ Uberaba, MG, Brazil \\ e Dental Research Division, Paulista University, Rua Doutor Bacelar, 1212, Zip Code: 04026-002, Sao Paulo, Brazil
}

\section{A R T I C L E I N F O}

\section{Article history:}

Received 23 December 2015

Received in revised form

19 March 2016

Accepted 21 March 2016

\section{Keywords:}

Degree of conversion

Flexural modulus

Mechanical properties

\begin{abstract}
A B S T R A C T
Objective. The present study evaluated the influence of diphenyliodonium hexafluorphosphate (DPI) combined with two different amines [ethyl 4-(dimethylamino)benzoate (EDAB) and 2-(dimethylamino)ethyl methacrylate (DMAEMA)] on the properties of model resin cements.

Methods. A comonomer base containing a 1:1 mass ratio of 2.2-bis[4-(2-hydroxy-3methacryloxypropoxy)phenyl]propane (bis-GMA) and triethyleneglycol dimethacrylate (TEGDMA) was obtained, after which $1 \mathrm{~mol} \%$ of camphorquinone and $0.1 \mathrm{~mol} \%$ of hydroxyl butyl toluene were added to the comonomer blend. Concentrations of co-initiators varied at $0,0.5$ or $1 \mathrm{~mol} \%$ for DPI and in 1 or $2 \mathrm{~mol} \%$ for amines (DMAEMA or EDAB). Silanated $\mathrm{Ba}-\mathrm{Al}-\mathrm{Si}$ glass $(60 \mathrm{wt} \%)$ was added as filler. The combination of each amine and DPI concentration resulted in 12 formulations, which had the following properties analyzed: degree of conversion (DC), water sorption $\left(\mathrm{W}_{\mathrm{sp}}\right)$ and solubility $\left(\mathrm{W}_{\mathrm{sl}}\right)$, flexural strength $(\mathrm{FS})$ and flexural
\end{abstract}

\footnotetext{
* Corresponding author. Present address: Dental Research Division, School of Dentistry - Paulista University, Rua Doutor Bacelar, 1212, CEP: 04026-002, Sao Paulo, Brazil. Tel.: +55 1155864000.

E-mail addresses: kamila_guedes@hotmail.com (K.M.G.d. Andrade), alanrmp@yahoo.com.br (A.R. Palialol), aclancellotti@hotmail.com (A.C. Lancellotti), baguiar@unicamp.br (F.H.B. Aguiar), david.watts@manchester.ac.uk (D.C. Watts), goncalves1976@yahoo.com.br

(L.S. Gonçalves), lima.adf@gmail.com, lima.adrianof@gmail.com (A.F. Lima), gimarchi@fop.unicamp.br (G.M. Marchi).

1 Tel.: +44 1612756749

http://dx.doi.org/10.1016/j.dental.2016.03.014

0109-5641/@ 2016 Academy of Dental Materials. Published by Elsevier Ltd. All rights reserved.
} 
modulus $\left(E_{f}\right)$. Data for DC, FS and $E_{f}$ were analyzed by two-way ANOVA and Tukey's test $(\alpha=0.05)$ and $W_{\text {sp }}$ and $W_{\mathrm{sl}}$ by Kruskal-Wallis and Dunn tests $(\alpha=0.05)$.

Results. EDAB promoted a higher DC than did DMAEMA; however, DPI increased DC for all materials with DMAEMA. The physical properties of resin formulations containing EDAB were significantly better than those of groups with DMAEMA; however, DPI had a positive influence on the chemical and physical properties of the model resin cement containing DMAEMA, especially with higher concentrations of amine.

Significance. EDAB proved to be more reactive than DMAEMA, being less influenced by DPI. Resins containing a 1:2 CQ/amine ratio had better properties than those with 1:1.

(c) 2016 Academy of Dental Materials. Published by Elsevier Ltd. All rights reserved.

\section{Introduction}

Resin cements are low-viscosity composites that have been used to lute glass-ceramic restorations [1], and may be classified according to their initiator systems as self-cured, light-cured or dual-cured, combining both physical and chemical mechanisms [2]. Based on favorable properties such as low solubility, a wide variety of shades and good adhesion to dental and ceramic structures, these luting agents became the first choice for the cementation of metal-free restorations and prefabricated posts. Despite the fact that light-cured materials provide longer working time and show higher color stability $[3,4]$ than dual or self-cure cements, their performance is impaired when the power of the light-source is attenuated [5], limiting the indications for these cements to clinical situations in which it is possible for the cements to be cured with high irradiance.

To improve the light-curing of resin-based materials, several methods have been evaluated, including: (i) the use of different photo-activation protocols [6-10], (ii) heating composite prior to the restorative procedure [11,12] and (iii) the use of different photoinitiator systems [13-15]. Diphenyliodonium hexafluorphosphate (DPI) is a salt that improves polymerization by forming higher quantities of free-radicals in conventional systems, such as those using camphorquinone (CQ), increasing the degree of conversion and positively influencing the properties of the polymer formed [14-16].

The reaction is improved due to the very low energy of the $\mathrm{C}-\mathrm{I}$ bond present in the DPI molecule. After reacting with camphorquinone/amine, the C-I bond is irreversibly broken, providing two phenyl radicals that can further react with residual amines, abstracting a proton and creating a new freeradical $[15,17]$. In addition, DPI is capable of reacting with inactive CQ radicals formed during the polymerization process [12] and acting as an electron acceptor, decreasing the termination rate and enhancing initiation as new radicals are generated due to DPI fragmentation [17].

Resinous restorative materials usually have a binary initiator system. CQ a widely used initiator in the light-curing of dental materials, cannot by itself generate high concentrations of free-radicals to promote suitable curing. Thus, amines are used as co-initiators to improve polymerization with this sensitizer [18]. In high concentrations, amines can increase composite susceptibility to oxidation, causing staining or discoloration of the restoration [19]. Conversely, low concentrations may hamper the reaction with $\mathrm{CQ}$, resulting in lower monomer conversion [13].

Ethyl 4-(dimethylamino)benzoate (EDAB) and 2(dimethylamino)ethyl methacrylate (DMAEMA) are conventionally used in CQ-amine systems, and their structures are very different. EDAB is an aromatic amine capable of donating a $\mathrm{H}^{+}$, even at low concentrations [20,21], while DMAEMA has an aliphatic structure and a tendency to bond with $\mathrm{O}_{2}$, inducing formation of oligomers [22]. Due to these differences, evaluating the behavior of these compounds in a ternary initiator system containing DPI is important to determine which amine is the better choice for the system, as well as to identify a concentration suitable for improving the polymerization process as well as the properties of resin composites with CQ as an initiator.

Therefore, the aim of the present study was to evaluate the influence of amines (EDAB and DMAEMA) at two concentrations ( $1 \mathrm{~mol} \%$ and $2 \mathrm{~mol} \%$ ), and the interaction of these agents with different concentrations of DPI (0, 0.5 and $1 \mathrm{~mol} \%)$, on model resin cements containing CQ as the initiator. The properties evaluated were degree of conversion, flexural strength and modulus, water sorption and solubility.

\section{Materials and methods}

\subsection{Preparation of the model cements}

Experimental resin materials were prepared at a 1:1 mass ratio of 2.2-bis[4-(2-hydroxy-3-methacryloxypropoxy) phenyl]propane (Bis-GMA) and triethyleneglycol dimethacrylate (TEGDMA) (Esstech Inc., Essington, PA, USA). Camphorquinone (1 mol\%) and butylated hydroxytoluene (BHT) (Esstech Inc.) (0.1 mol\%) were added (BHT as inhibitor), blended and homogenized for $1 \mathrm{~h}$ at room temperature with a magnetic stirrer. The model blend was divided into 12 fractions, labeled RC1 to RC12, and groups were formed according to the concentrations of diphenyliodonium hexafluorphosphate $(0,0.5$ and 1 mol\% - DPI, Sigma-Aldrich, Milwaukee, WI, USA), ethyl 4-(dimethylamino)benzoate (1 and 2 mol\% - EDAB, Sigma-Aldrich) and 2-(dimethylamino)ethyl methacrylate (1 and 2 mol\% DMAEMA, Sigma-Aldrich) in the formulations. Each formulation was loaded with $60 \mathrm{wt} \%$ of $0.7-\mu \mathrm{m}$ average size silanated barium borosilicate glass fillers (Esstech Inc.). All chemicals were used without further purification. 


\subsection{Degree of conversion}

To measure the degree of conversion (DC) of the model resin cements $(n=5)$, we prepared five specimens of each group using a circular stainless steel mold $(4.5 \mathrm{~mm}$ diameter and $1 \mathrm{~mm}$ thick). The mold was filled with the resin cement and light-cured by means of a light-emitting diode (LED, Bluephase G2, Ivoclar-Vivadent, Schaan, Liechtenstein) at an irradiance of $1200 \mathrm{~mW} / \mathrm{cm}^{2}$ for $20 \mathrm{~s}$. After $24 \mathrm{~h}$, the measurements were performed by Fourier transform infrared spectroscopy (FTIR, Spectrum 100 Optica, PerkinElmer, Billerica, MA, USA) equipped with an attenuated total reflectance (ATR) device with a diamond crystal (Pike Technologies, Madison, WI, USA). Prior to the reading of the polymerized materials, the baseline was recorded with the unreacted monomers with a wave-number range of $1665-1580 \mathrm{~cm}^{-1}, 32$ scans and resolution of $4 \mathrm{~cm}^{-1}$ and Happ-Genzel apodization in absorbance mode. DC was calculated according to a baseline technique [18] based on band ratios of $1638 \mathrm{~cm}^{-1}$ (aliphatic carbon-tocarbon double bond) and $1608 \mathrm{~cm}^{-1}$ (aromatic component group) as an internal standard between the polymerized and unpolymerized samples, based on the following expression: $\mathrm{DC}=100 \times[1-($ polymerized cement/unpolymerized cement $)]$.

\subsection{Flexural strength and modulus}

Bar-shaped specimens ( $7 \mathrm{~mm}$ length, $2 \mathrm{~mm}$ width and $1 \mathrm{~mm}$ height) were prepared for three-point bending measurements $(n=10)$ [9]. The reduced specimen dimensions were necessary to allow the specimens to be light-cured in a single step (20 s). The specimens were light-cured by light-emitting diodes (LED, Bluephase G2, Ivoclar-Vivadent).

Flexural strength test was measured $24 \mathrm{~h}$ after irradiation on a universal testing machine (Instron 4411, Canton, MA, USA) with a span width of $5 \mathrm{~mm}$ at a crosshead speed of $0.5 \mathrm{~mm} / \mathrm{min}$. Flexural strength (FS, in $\mathrm{MPa})$ and modulus $\left(E_{f}\right.$, in $\mathrm{GPa}$ ) were monitored by Blue Hill 2 software (Instron), and the $\sigma$ and $E_{f}$ values were calculated from the load-displacement trace. The tests were not performed for the cements containing $1 \mathrm{~mol} \%$ of DMAEMA without DPI or with $0.5 \mathrm{~mol} \%$ DPI, since the specimens fractured during removal from the silicone matrix, possibly due to the low conversion of the experimental resins.

\subsection{Water sorption and solubility}

Five specimens of each group were prepared in a manner similar to that used for the degree of conversion, in a circular stainless steel mold ( $4.5 \mathrm{~mm}$ diameter and $1 \mathrm{~mm}$ thick) and cured for $20 \mathrm{~s}$. The specimens were individually dry-stored in Eppendorf tubes at $37^{\circ} \mathrm{C}$ and weighed daily by means of an analytical balance (Discovery DV215CD, Ohaus Corporation, Pine Brook, NJ, USA) with an accuracy of $0.01 \mathrm{mg}$, until the weight stabilized (m1). The specimens were then immersed in distilled water for 7 days. After immersion, the excess water was removed with absorbent papers, and the specimens were gently dried with air for $10 \mathrm{~s}$ and weighed (m2). The specimens were then dry-stored and weighed again as initially described (m3).
The diameters and thicknesses of the specimens were measured by means of a digital caliper with $0.01-\mathrm{mm}$ accuracy for calculation of the volume (V) of each disc, in $\mathrm{mm}^{3}$. The values of water sorption $\left(\mathrm{W}_{\mathrm{sp}}\right)$ and solubility $\left(\mathrm{W}_{\mathrm{sl}}\right)$ were calculated according to the formula:

$\mathrm{W}_{\mathrm{sp}}=\frac{(m 2-m 3)}{\mathrm{V}-\mathrm{W}_{\mathrm{sl}}}=\frac{(m 1-m 3)}{\mathrm{V}}$.

As observed for the flexural test, water sorption and solubility of the cements containing $1 \mathrm{~mol} \%$ of DMAEMA without DPI or with $0.5 \mathrm{~mol} \%$ DPI were not analyzed, since the specimens fractured during removal from the matrix.

\subsection{Statistical analysis}

The normality and variance homogeneity of the data were analyzed. The results of $\mathrm{W}_{\mathrm{sp}} / \mathrm{W}_{\mathrm{sl}}$ were subjected to Kruskal-Wallis and Dunn's post hoc tests $(\alpha=0.05)$. The data of FS, $E_{f}$ and DC were subjected to two-way ANOVA and Tukey's post hoc test $(\alpha=0.05)$.

\section{Results}

\subsection{Degree of conversion}

The experimental resin cements without DPI, with EDAB as co-initiator, gave higher results than DMAEMA materials, and cements with 1 mol\% DMAEMA gave the lowest values (Table 1). DPI improved DC for all materials with DMAEMA. For cements with EDAB, DPI reduced DC with the concentration of $1 \mathrm{~mol} \%$, and the effect of this co-initiator on the resins with 2 mol\% of EDAB was not observed. The co-initiator EDAB promoted higher values of conversion compared with DMAEMA.

\subsection{Flexural strength}

The materials with DMAEMA as co-initiator had significantly increased FS with DPI, mainly in the materials containing $1 \mathrm{~mol} \%$ of the amine (Table 1 ). For EDAB, DPI influenced only the materials containing $2 \mathrm{~mol} \%$ of this amine, with $1 \mathrm{~mol} \%$ DPI decreasing the FS. When the amines were compared, EDAB promoted the highest FS in materials without DPI. After the addition of $0.5 \mathrm{~mol} \%$ of DPI, the resins containing $1 \mathrm{~mol} \%$ DMAEMA had the lowest values, with the other cements presenting statistically similar values. For the cements with $1 \mathrm{~mol} \%$ of DPI, the materials with 2 mol\% DMAEMA and $1 \mathrm{~mol} \%$ EDAB gave the highest FS, with the resins containing $1 \mathrm{~mol} \%$ DMAEMA and 2 mol\% EDAB presenting the lowest. As occurred for sorption and solubility, the three-point bending tests were not performed for cements containing $1 \mathrm{~mol} \%$ of DMAEMA without DPI or with $0.5 \mathrm{~mol} \%$ DPI, since the specimens fractured during removal from the silicone matrix, possibly due to low monomer conversion.

\subsection{Flexural modulus}

The $E_{f}$ of cements with DMAEMA was positively influenced by DPI, in contrast to cements with EDAB, which were not influenced by the iodonium salt (Table 1). 
Table 1 - Results of DC (in \%), FS (MPa) and $E_{f}(\mathrm{GPa})$ of the resin cements.

\begin{tabular}{lllcll} 
Test & \multicolumn{1}{c}{ DFI } & 1 mol\% DMAEMA & 2 mol\% DMAEMA & 1 mol\% EDAB & 2 mol\% EDAB \\
\hline DC & $0 \mathrm{~mol} \%$ & $13.71(2.30) \mathrm{Cc}$ & $44.95(2.41) \mathrm{Bb}$ & $72.71(2.54) \mathrm{Aa}$ & $76.79(2.5) \mathrm{Aa}$ \\
& $0.5 \mathrm{~mol} \%$ & $31.60(2.49) \mathrm{Db}$ & $58.46(2.25) \mathrm{Ca}$ & $67.39(2.35) \mathrm{Bb}$ & $77.26(1.25) \mathrm{Aa}$ \\
& $1 \mathrm{~mol} \%$ & $54.2(2.31) \mathrm{Ca}$ & $54.37(2.28) \mathrm{Ca}$ & $68.02(1.75) \mathrm{Bb}$ & $76.43(1.52) \mathrm{Aa}$ \\
$\mathrm{FS}$ & $0 \mathrm{~mol} \%$ & - & $95.66(10.88) \mathrm{Bb}$ & $118.78(17.17) \mathrm{ABa}$ & $140.58(14.91) \mathrm{Aa}$ \\
& $0.5 \mathrm{~mol} \%$ & - & $122.96(23.38) \mathrm{Aa}$ & $130.78(15.46) \mathrm{Aa}$ & $136.46(14.09) \mathrm{Aa}$ \\
& $1 \mathrm{~mol} \%$ & $109.44(17.7) \mathrm{Ba}$ & $120.64(20.84) \mathrm{Aa}$ & $130.73(14.61) \mathrm{Aa}$ & $102.19(26.94) \mathrm{Bb}$ \\
$E_{f}$ & $0 \mathrm{~mol} \%$ & - & $2.72(0.36) \mathrm{Bc}$ & $3.82(0.19) \mathrm{Aa}$ & $3.92(0.27) \mathrm{Aa}$ \\
& $0.5 \mathrm{~mol} \%$ & - & $3.38(0.37) \mathrm{Bb}$ & $3.84(0.36) \mathrm{Aa}$ & $3.87(0.28) \mathrm{Aa}$ \\
& $1 \mathrm{~mol} \%$ & $3.45(0.23) \mathrm{Aa}$ & $3.92(0.33) \mathrm{Aa}$ & $3.79(0.33) \mathrm{Aa}$ & $3.71(0.37) \mathrm{Aa}$ \\
\hline
\end{tabular}

Means of each test followed by different capital letters (row) and small letters (column) differed significantly from Tukey's post hoc test $(p<0.05)$.

However, these materials gave higher $E_{f}$ compared with cements with DMAEMA, except for resins with 1 mol\% of DPI, which had similar $E_{f}$ regardless of the amine used.

\subsection{Water sorption and solubility}

The addition of $1 \mathrm{~mol} \%$ DPI increased the $W_{\mathrm{sp}}$ of cements containing $1 \mathrm{~mol} \%$ of EDAB but had no effect on the other experimental concentrations (Fig. 1).

The cement with 2 mol\% DMAEMA had the highest solubility compared with the cements containing EDAB without DPI. The addition of DPI had a positive influence on the $\mathrm{W}_{\mathrm{sl}}$ of cements with 2 mol\% DMAEMA, with this cement behaving similarly to the resins with EDAB (Fig. 2). DPI had no effect on the solubility of cements with EDAB as co-initiator.

\section{Discussion}

Resin cements are widely used in dentistry to bond indirect restorations such as inlays/onlays, full crowns, pre-fabricated posts and laminate veneers. Nevertheless, the light-curing resin cements should be used when thickness, type or opacity of the ceramic allows for suitable light transmission during photopolymerization, to promote adequate conversion as well as better properties of the material. The greater thickness of indirect restorations, except for laminate veneers, as well as the extension of the root canal, decreases the amount of light irradiance reaching the cement, making the use of a dualcure resin cement necessary in these situations. But dual-cure resins have the disadvantage of reduced color stability due to the higher amount of amine in this system [5,23,24], as well as reduced working time, which, in some cases, can compromise

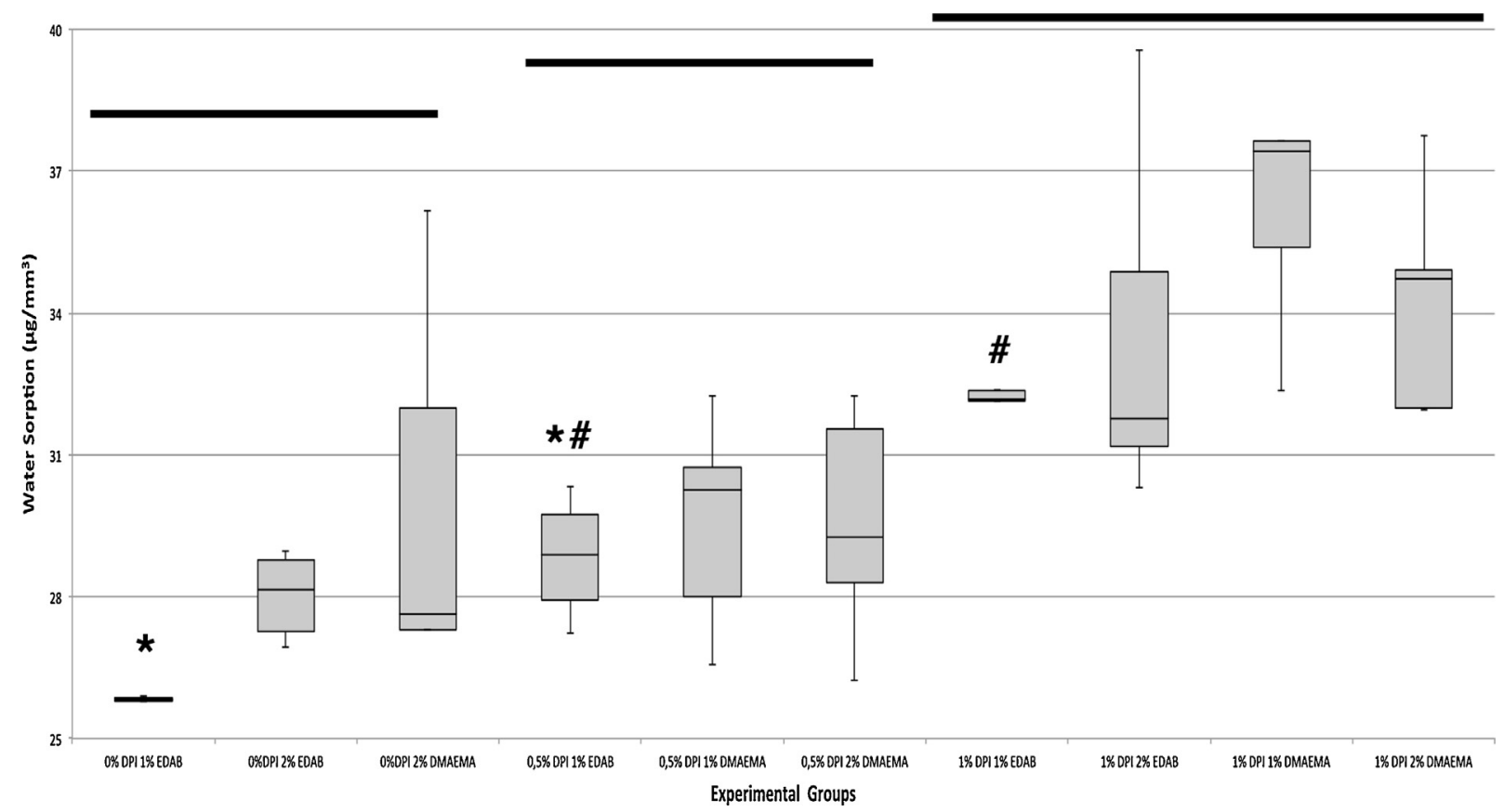

Fig. 1 - Median values of $W_{s p}\left(\mu \mathrm{g} / \mathrm{mm}^{3}\right)$ analyzed by Kruskal-Wallis and Dunn's post hoc tests $(\alpha=0.05)$. Horizontal lines compare amines within each DPI concentration. Different symbols (*\#) indicate statistically significant differences of DPI concentrations within amines. 


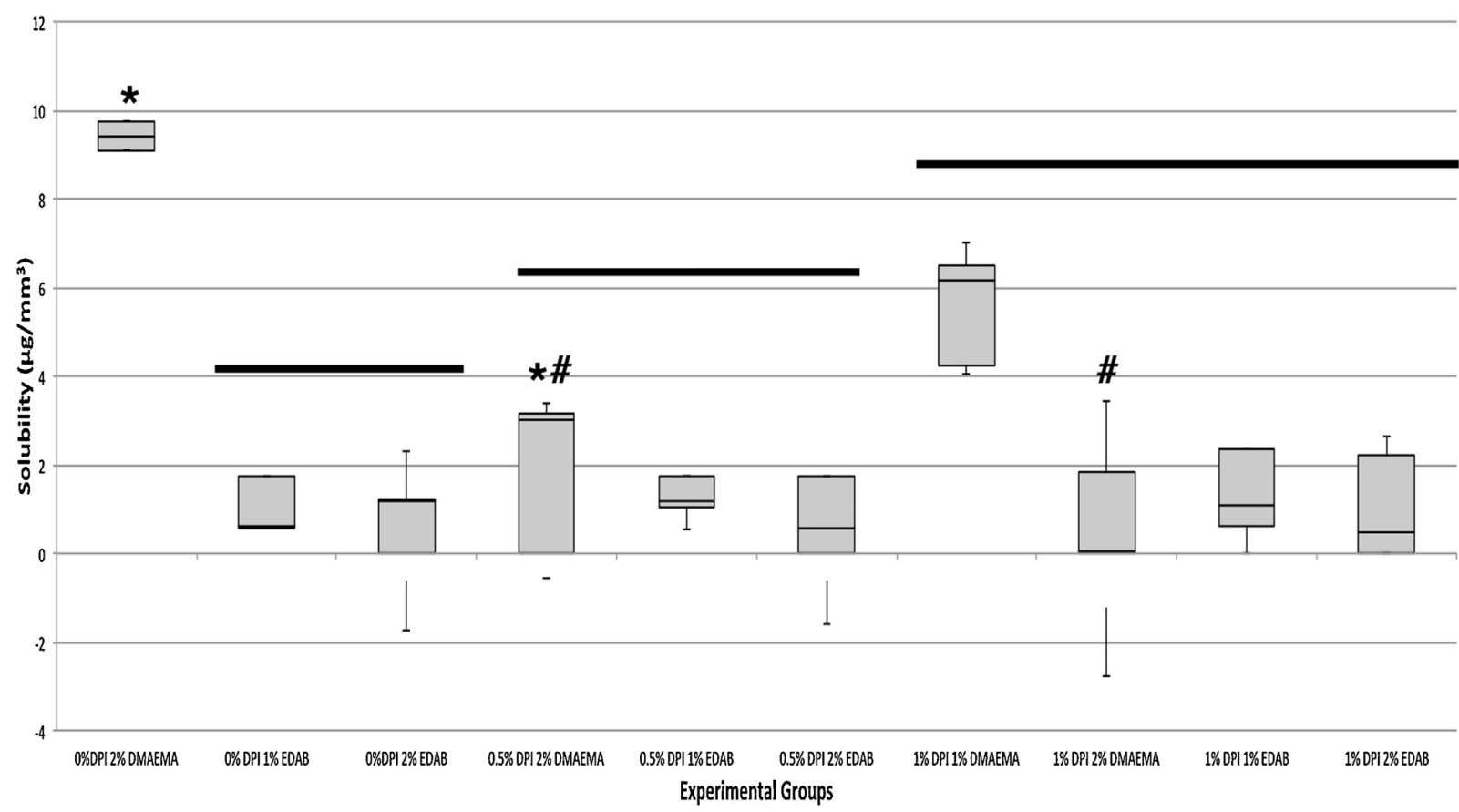

Fig. 2 - Median values of $\mathrm{W}_{\mathrm{sl}}\left(\mu \mathrm{g} / \mathrm{mm}^{3}\right)$ analyzed by Kruskal-Wallis and Dunn's post hoc tests $(\alpha=0.05)$. Horizontal lines compare amines within each DPI concentration. Different symbols (*\#) indicate statistically significant differences of DPI concentrations within amines.

the complete removal of excess resin cement after cementation. Therefore, it is important that light-curing resin cements are modified to become more reactive, improving the polymerization process and consequently increasing the degree of conversion of the material, not only to be used in one exclusive treatment, but also providing the advantages of these cements for all adhesive procedures.

The present study showed the interaction of DPI with two concentrations of different amines in a free-radical initiator system. The cements containing EDAB showed the highest DC, which can be explained by the structure of this co-initiator. DMAEMA has hydrophilic characteristics, different from those of CQ [25], which may have hindered the interaction of the two components, consequently reducing the degree of resin cure. Another aspect to be considered is the nucleophilicity, that is, the ability of a chemical compound to transfer electrons to an electrophile molecule (e.g. CQ in the triplet state) to promote a chemical bond. Nucleophilicity depends on the structure of the co-initiator, reducing the reactivity with the sensitizer according to the reduced number of $\mathrm{C}=\mathrm{C}$ bonds present in the molecule [26]. EDAB has an aromatic ring on the backbone and higher nucleophilicity compared with that of DMAEMA, providing more $\mathrm{H}^{+}$ions to $\mathrm{CQ}$, increasing reactivity of the systems and consequently improving monomeric conversion [20]. The best results obtained from the use of EDAB compared with DMAEMA are similar to those obtained in another study evaluating the curing properties of different initiator systems [26].

The results reported by a previous study differ from those seen in this study, showing DMAEMA with higher reactivity than EDAB [27]. This difference can be attributed to the $\mathrm{CQ} /$ amine ratio used (1:1 and 1:2 in this study; 1:4 in the previous study [27]). As already mentioned, amines can cause yellowing in resin materials, and large quantities of these agents can exacerbate this problem, highlighting the importance of improving polymerization, e.g., using DPI, decreasing the quantities of sensitizer and reducing agents.

However, the polymerization of cements containing DMAEMA can be improved by DPI. This iodonium salt minimizes the non-productive electron back-transfer from the ketone radical anion and the amine radical cation. DPI intercepts the ketone radical anion and prevents electron back-transfer from occurring, and irreversibly decomposes to an aryl radical and an aryl iodide, forming a new radical and improving polymerization.

Except for the resin containing 1 mol\% DMAEMA without and with $0.5 \mathrm{~mol} \%$ of DPI, which could not be tested due to the reduced degree of conversion, all cements in the present study showed $W_{\text {sp }}$ between $25.82 \mu \mathrm{g} / \mathrm{mm}^{3}$ and $37.41 \mu \mathrm{g} / \mathrm{mm}^{3}$, similar to results with commercial resin cements evaluated in a previous study [28]. All model cements studied had $W_{\mathrm{sp}} / \mathrm{W}_{\mathrm{sl}}$ in accordance with ISO 4049 limits. The highest $W_{s l}$ of resins containing $1 \mathrm{~mol} \%$ DMAEMA $+1 \mathrm{~mol} \%$ DPI and $2 \mathrm{~mol} \%$ DMAEMA without DPI can be explained by factors such as DC. DMAEMA has an open chain and is less reactive than aromatic amines, therefore promoting slower polymerization when short irradiation times are applied [22]. Paradoxically, DPI increased $\mathrm{W}_{\mathrm{sl}}$ of cements containing $1 \mathrm{~mol} \% \mathrm{EDAB}+1 \mathrm{~mol} \%$ of DPI. EDAB combined with CQ gave a high degree of resin conversion, even without DPI. Nevertheless, in cements containing the $1: 1$ ratio of $C Q / E D A B$, the concentration of amine was probably insufficient to react properly with the CQ and DPI, which can trigger a premature termination of the chains, reducing DC and negatively influencing $\mathrm{W}_{\mathrm{sp}}$ (groups R7 and R11). However, the present results corroborate those 
of previous studies demonstrating that a high concentration of DPI can inhibit polymerization due to fast curing and premature beginning of the termination phase [14]. Thereby, the penetration of water into composite by interaction with ester, ether and hydroxyl groups, as well as porosities through the interface between organic matrix and filler [29], can be accentuated by the reduced degree of conversion.

FS and $E_{f}$ were significantly improved in DMAEMA cements forming stiff and strong materials by the addition of DPI. This behavior can probably be attributed to increased crosslinking density in these cements combined with the higher DC, corroborating the results obtained in a previous study [14]. The amine EDAB, even without the use of DPI, significantly increased the DC of model cements. Resin cements with $2 \mathrm{~mol} \%$ EDAB were less influenced by DPI, since, with the increased efficiency of amine, the maximum polymerization was probably achieved for the formulation examined. However, a significant reduction in FS was observed in $2 \mathrm{~mol} \%$ EDAB $+1 \mathrm{~mol} \% \mathrm{DPI}$. It can be speculated that using $1 \mathrm{~mol} \%$ DPI with 2 mol\% EDAB can increase not only the extent of polymerization but also primary cyclization, which can result in a polymer with a high degree of conversion but reduced strength, promoting, in this case, a reduction in FS.

Previous studies have shown that the addition of DPI to resin formulations could increase the rate of curing and degree of polymerization and improve the physical properties of resins with CQ/DMAEMA as the initiator system [14]. Based on this, the present study evaluated the different amines that can be used combined with CQ and DPI to obtain better results for the chemical and physical properties of resins in a ternary initiator system. According to the results, EDAB was highly compatible with CQ systems, improving the cure and physical properties of resins, whether combined or not with DPI. The present study showed the importance of DPI to resin materials with DMAEMA as the co-initiator, but also the efficiency and better compatibility of EDAB with $C Q$, promoting better chemical and physical properties even without the use of DPI. Thus, future investigations are needed to determine suitable concentrations of the components of this system and to establish the best relationship among initiators, co-initiators and the properties of different resin materials.

\section{Conclusions}

Based on the results obtained, it can be concluded that:

- EDAB gave significantly better results than DMAEMA in terms of the chemical and physical properties of the resins evaluated;

- DPI had a positive influence on the chemical and physical properties of the model resin cements tested, primarily those containing DMAEMA;

- DPI increased the degree of conversion of the resins containing DMAEMA, but reduced the conversion of systems containing $C Q / E D A B$ at a 1:1 ratio; and

- the $1: 2$ ratio of $C Q / a m i n e$ can promote significantly better properties than the $1: 1$ ratio.

\section{Acknowledgments}

This study was supported by Fundação de Amparo à Pesquisa do Estado de São Paulo (Fapesp, grants \#2011/04513-7 and \#2011/21842-4).

The authors are grateful to Esstech Inc., Essington, PA, USA for a generous donation of some materials used in the present study.

\section{REFERENCES}

[1] Kern M, Barloi A, Yang B. Surface conditioning influences zirconia ceramic bonding. J Dent Res 2009;88:817-22.

[2] Hofmann N, Papsthart G, Hugo B, Klaiber B. Comparison of photo-activation versus chemical or dual-curing of resin-based luting cements regarding flexural strength, modulus and surface hardness. J Oral Rehabil 2001;28:1022-8.

[3] Buchalla W, Attin T, Hilgers RD, Hellwig E. The effect of water storage and light exposure on the color and translucency of a hybrid and a microfilled composite. J Prosthet Dent 2002;87:264-70.

[4] Koishi Y, Tanoue N, Atsuta M, Matsumura H. Influence of visible-light exposure on colour stability of current dual-curable luting composites. J Oral Rehabil 2002;29:387-93.

[5] Kilinc E, Antonson SA, Hardigan PC, Kesercioglu A. Resin cement color stability and its influence on the final shade of all-ceramics. J Dent 2011;39(Suppl. 1):e30-6.

[6] Komori PC, de Paula AB, Martin AA, Tango RN, Sinhoreti MA, Correr-Sobrinho L. Effect of light energy density on conversion degree and hardness of dual-cured resin cement. Oper Dent 2010;35:120-4.

[7] Faria-e-Silva AL, Lima AF, Moraes RR, Piva E, Martins LR. Degree of conversion of etch-and-rinse and self-etch adhesives light-cured using QTH or LED. Oper Dent 2010;35:649-54

[8] Gaglianone LA, Lima AF, Araujo LS, Cavalcanti AN, Marchi GM. Influence of different shades and LED irradiance on the degree of conversion of composite resins. Braz Oral Res 2012;26:165-9.

[9] Gonçalves LS, Moraes RR, Ogliari FA, Boaro L, Braga RR, Consani S. Improved polymerization efficiency of methacrylate-based cements containing an iodonium salt. Dent Mater 2013;29:1251-5, http://dx.doi.org/10.1016/j.dental.2013.09.010.

[10] Lima AF, de Andrade KM, da Cruz Alves LE, Soares GP, Marchi GM, Aguiar FH, et al. Influence of light source and extended time of curing on microhardness and degree of conversion of different regions of a nanofilled composite resin. Eur J Dent 2012;6:153-7

[11] dos Santos RE, Lima AF, Soares GP, Ambrosano GM, Marchi GM, Lovadino JR, et al. Effect of preheating resin composite and light-curing units on the microleakage of Class II restorations submitted to thermocycling. Oper Dent 2011;36:60-5.

[12] Mundim FM, Garcia Lda F, Cruvinel DR, Lima FA, Bachmann L, Pires-de-Souza Fde C. Color stability, opacity and degree of conversion of pre-heated composites. J Dent 2011;39(Suppl. 1):e25-9.

[13] Brandt WC, Schneider LF, Frollini E, Correr-Sobrinho L, Sinhoreti MA. Effect of different photo-initiators and light curing units on degree of conversion of composites. Braz Oral Res 2010;24:263-70. 
[14] Goncalves LS, Moraes RR, Ogliari FA, Boaro L, Braga RR, Consani S. Improved polymerization efficiency of methacrylate-based cements containing an iodonium salt. Dent Mater 2013;29:1251-5.

[15] Ogliari FA, Ely C, Petzhold CL, Demarco FF, Piva E. Onium salt improves the polymerization kinetics in an experimental dental adhesive resin. J Dent 2007;35:583-7.

[16] Meereis CTW, Leal FB, Lima GS, de Carvalho RV, Piva E, Ogliari FA. BAPO as an alternative photoinitiator for the radical polymerization of dental resins. Dent Mater 2014;30:945-53.

[17] Crivello JV, Lam JH. Diaryliodonium salts-new class of photo-initiators for cationic polymerization. Macromolecules 1977;10:1307-15.

[18] Jakubiak J, Allonas X, Fouassier JP, Sionkowska A, Andrzejewska E, Linden LA, et al. Camphorquinone-amines photoinitating systems for the initiation of free radical polymerization. Polymer 2003;44:8.

[19] Archegas LR, Freire A, Vieira S, Caldas DB, Souza EM. Colour stability and opacity of resin cements and flowable composites for ceramic veneer luting after accelerated ageing. J Dent 2011;39:804-10.

[20] Emami N, Soderholm KJ. Influence of light-curing procedures and photo-initiator/co-initiator composition on the degree of conversion of light-curing resins. J Mater Sci Mater Med 2005:16:47-52

[21] Lovell LG, Newman SM, Donaldson MM, Bowman CN. The effect of light intensity on double bond conversion and flexural strength of a model, unfilled dental resin. Dent Mater 2003;19:458-65.

[22] Schroeder WF, Vallo CI. Effect of different photoinitiator systems on conversion profiles of a model unfilled light-cured resin. Dent Mater 2007;23:1313-21.

[23] Ghavam M, Amani-Tehran M, Saffarpour M. Effect of accelerated aging on the color and opacity of resin cements. Oper Dent 2010;35:605-9.

[24] Lu H, Powers JM. Color stability of resin cements after accelerated aging. Am J Dent 2004;17:354-8.

[25] Guo X, Wang Y, Spencer P, Ye Q, Yao X. Effects of water content and initiator composition on photopolymerization of a model BisGMA/HEMA resin. Dent Mater 2008;24: 824-31.

[26] de Oliveir DCRS, Rocha MG, Gatti A, Correr AB, Ferracane JL, Sinhoreti MAC. Effect of different photoinitiators and reducing agents on cure efficiency and color stability of resin-based composites using different LED wavelengths. J Dent 2015;43:1565-72.

[27] Furuse AY, Mondelli J, Watts DC. Network structures of Bis-GMA/TEGDMA resins differ in DC, shrinkage-strain hardness and optical properties as a function of reducing agent. Dent Mater 2011;27:497-506

[28] Mese A, Burrow MF, Tyas MJ. Sorption and solubility of luting cements in different solutions. Dent Mater J 2008;27:702-9.

[29] Ping ZH, Nguyen QT, Chen SM, Zhou JQ, Ding YD. States of water in different hydrofilic polymers - DSC and FTIR studies. Polymer 2001;42:7. 